\title{
A Study on the Evolution of Mechanism of Infectious Disease Analysis Model of Event Using Micro-Blog Platform
}

\author{
Haiying Ma \\ Department of Management Science and Engineering, East China University of Science \& Technology, China \\ Email: c mhy@163.com
}

Received 30 April 2015; accepted 26 July 2015; published 29 July 2015

Copyright (C) 2015 by author and Scientific Research Publishing Inc. This work is licensed under the Creative Commons Attribution International License (CC BY). http://creativecommons.org/licenses/by/4.0/ c) (i) Open Access

\begin{abstract}
After the occurrence of unexpected group events of network, the relevant opinion information will spread rapidly through micro-blog, and the negative public opinion information will aggravate the unexpected the group events to upgrade and expand the scope of harm. It is difficult to deal. So public opinion control is very important. In this paper, we establish an influence model for spreading of public opinion based on SIR model. Through the political analysis, this paper finds that the network group events will subside, but the influence scope, time and ability of event cannot be ignored. As a result of this study, the corresponding strategies are put forward in this paper.
\end{abstract}

Keywords

Micro-Blog, Group Events of Network, Public Opinion Control, SIR Model

\section{Introduction}

The occurrence of group events has a great and strong impact on the society, and it is difficult to deal with, not only directly lead to heavy loss of social and economic life, and increase the difficulty of administrative management at all levels of government, but also have great harm for social stability and development, which have become the prominent problems of public security order and social stability. [1] groups events of network developed rapidly, in November 2011 Shanghai Jiaotong University public opinion research laboratories and public opinion network jointly issued the "Public Opinion Research Report Q3 2011” shows. Following the incident, nearly half of hot social events are an exposure within a few hours [2]. Among them, the network news is the first, and Micro-blog is the second. Not only in the domestic, in the spring of 2011 the "Arab Spring” movement, 
early the riots in London and other British cities and the "Occupy Wall Street” campaign in the fall of the United States, have shown that the micro-blog has a strong ability of Mobilization cross social class and cross region. Network media initiates network community events and becomes the real driving force of social group events. In summary, the in-depth study of group events of network has become a top priority of the current researchers, and has a very important significance for maintaining social stability and unity and building a harmonious society.

First, this paper discusses the feasibility of applying the model of infectious diseases. Then, the parameters of the model and the model are introduced. The analysis conclusion is obtained by the corresponding calculation. In the end, the paper puts forward some suggestions for the group events of network management.

\section{Research Method}

Micro-blog is essentially SNS (Network Site Social). It is not only a social network but also a social platform. In all modern network platforms, it not only plays the role in the media platform, the strong interaction, social sharing fundamental attributes given its wide range of functions and features. Because of this, in the past few years the micro-blog provides a fertile ground for the germination and growth of the group events of network. In real life events is limited by local groups, the number of participants, and other laws and regulations, so the large-scale spread is difficult. Group events of network spread fast, are less susceptible to control and limit. For the government it is increasing the difficult to manage group events of network. The rapid development of group events of network and the rapid spread of the Internet, the popularity of mobile device and other factors are related. In recent years, China has 3000 new web sites per day, and data show that over $90 \%$ of which come from commercial networks [3]. For the dissemination of information, it is difficult for government to manage and control it. Network legal system is not perfect, so that the network has sufficient space to develop freely. Once large-scale public opinion appears, the government is often in a passive situation and almost loses control. Because micro-blog platform is pluralism, rational of people is varying degree, so it is much more complex than the offline group events and other network platform group events, like Table 1.

After the group events of network occurs, the relevant public opinion will quickly spread, and negative public opinion will intensify the development of upgrade mass emergencies, increase the difficulty of treatment, expand the scope of the harm [4]. The impact of the Internet public opinion on the mass emergency is quite similar to that of the epidemic virus. Participants in group events as carriers will affect the normal communication through public opinion, so the normal people participate in the event with virus propagation model to build public opinion on the impact of group events model consistent with its objective laws [5]. So in this paper, on the basis of viral infection model, we established an influence model for spread of public opinion.

\section{Modeling}

In this paper, we used SIR epidemic model, under the simplified premise other variables, establishing a number of assumptions, according to the number of micro blog users may be affected by the fluctuations and influence of public opinion, the number of users involved in the event, as well as the number of users is not affected to establish the model.

\subsection{Model Hypothesis}

(1) After the incident, the crowd divided infection (event participants) and healthy subjects (those who do not participate in the event). The number of patients is $i(t)$ at time $t$.

(2) The impact of the group events has nothing to do with the people of the degree of education, occupation, age. People do not distinguish between negative or positive view, only discusses dissemination.

Table 1. Comparison groups event online and offline.

\begin{tabular}{ccc}
\hline Event Category & Online community event & Offline community event \\
\hline Factors Affecting & Time change of pace & Area, the number \\
the degree of control & Almost out of control & Banned \\
Public Opinion diffusion velocity & Rapid & Slower \\
\hline
\end{tabular}


(3) Assume that the infected and healthy people mix well in the crowd. The number of participants per participant per unit of time effective exposure (affecting the speech of others) was K (infection).

(4) The proportion of infected persons who were treated every day was $\mathrm{H}$ (cure rate). And the Exit will no longer be involved (immunity).

The total number $N$ constant, the proportion of infected persons, health and immune persons is $I(t), S(t), R(t)$, $I(t)+S(t)+R(t)=1$. tion.

$I(t), S(t), R(t)$ are infected, healthy, immune persons proportion of the total number of the $N$ at time $t$ infec-

\subsection{Modeling Process}

In the model, $I$ is expressed as the infected person, $S$ is expressed as a healthy person, $R$ is expressed as immune, $H$ is the cure rate, $k$ is daily contact rate. SIR model differential equations are expressed as follows:

$$
\left\{\begin{array}{l}
N[I(t+\Delta t)-I(t)]=N I(t) * k S(t) \Delta t-h N I(t) \Delta t \\
N[S(t+\Delta t)-S(t)]=-k N S(t) I(t) \Delta t \\
N[R(t+\Delta t)-R(t)]=h N I(t) \Delta t
\end{array}\right.
$$

On (1) are derived, get

$$
\left\{\begin{array}{l}
\frac{\mathrm{d} I}{\mathrm{~d} t}=k I S-h I \\
\frac{\mathrm{d} S}{\mathrm{~d} t}=-k I S \\
\frac{\mathrm{d} R}{\mathrm{~d} t}=h I
\end{array}\right.
$$

Because of $I(t)+S(t)+R(t)=1$

$$
\left\{\begin{array}{l}
\frac{\mathrm{d} I}{\mathrm{~d} t}=k I S-h I \\
\frac{\mathrm{d} S}{\mathrm{~d} t}=-k I S \\
S(0)=S_{0}, I(0)=I_{0}
\end{array}\right.
$$

$S_{0}+I_{0} \approx 1$ ( $R_{0}$ is usually very small), $\sigma=k / h . \sigma$ is the number of effective contacts per patient during a period of infection.

The SIR model is the elimination of $\mathrm{d} t$, and get the trajectory equations

So

$$
\left\{\begin{array}{l}
\frac{\mathrm{d} T}{\mathrm{~d} S}=\frac{1}{\sigma S}-1 \\
I\left(S_{0}\right)=I_{0}
\end{array}\right.
$$

$$
I(S)=\left(S_{0}+I_{0}\right)-S+\frac{1}{\sigma} \ln \frac{S}{S_{0}}
$$

Equation curve is shown for trajectory. In Figure 1, $S$ represents the number of health. $I$ represent the number of infection (participants). $S_{0}$ represents the initial number of healthy individuals. The arrow indicates the trend of change of $S(t)$ and $I(t)$ with time.

\subsection{Analysis and Discussions}

$S(t) \geq 0$, but $\frac{\mathrm{d} S}{\mathrm{~d} t}=-k I S \leq 0$. Therefore, the limit of the existence of $S(t)$, denoted as $S_{\infty}, \frac{\mathrm{d} R}{\mathrm{~d} t}=h I \geq 0$, 


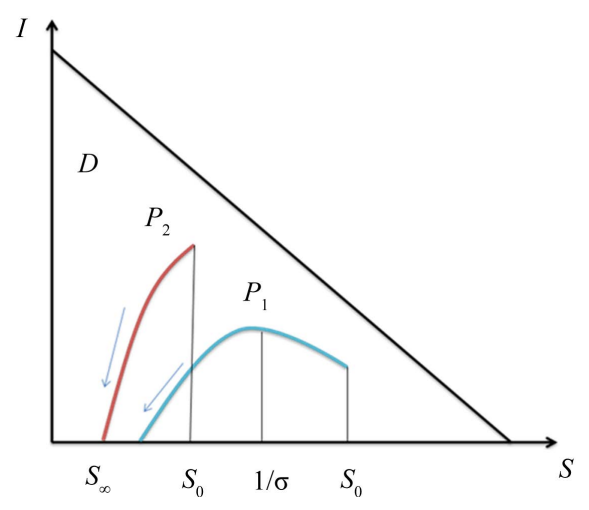

Figure 1. Trajectory.

$R \leq 1$. Therefore, the limit of the existence of $R(t)$, denoted as $R_{\infty}$ The limit of the existence of $I(t)=1-S(t)-R(t)$, denoted as $I_{\infty}$ If $I_{\infty}>0$, then there is $\varepsilon>0$, which makes $I_{\infty}>\varepsilon$.

$\exists T$. When $t>T$, make $I(t)>\varepsilon$. Then there is $\frac{\mathrm{d} R}{\mathrm{~d} t}=h I \geq h \varepsilon$.

$R_{\infty}=\infty$, Contradiction with $R_{\infty}$. Therefore, regardless of the initial conditions for $S_{0}, I_{0}, \lim _{x \rightarrow \infty} I(t)=I_{\infty}=0$

(1) When $S_{0}>1 / \sigma$, the number of participants was reduced to 0 , and the spread of the participants, that is the $P_{1}$ curve in Figure 1.

(2) When $S_{0}<1 / \sigma$, the number of participants decreased to 0 , and the number of participants was not spread, that is the $P_{2}$ curve in Figure 1.

Based on the assumption of the model, the crowd will eventually exit the discussion over time, because of the new public opinion focus or the people's saturated absorption of information. But this does not mean that the government can therefore relax control. The discussion period is too long, change of trend of the number of people involved is too large, the government will have a negative impact on public opinion.

\subsection{Experiment}

We take the "Handan destroyed wheat event" as an example to verify the relevant conclusions. In 2013 May, Handan Quzhou County launched a "destroy the wheat boom". Wheat, tomato, peach and apple trees will be destroyed, the villagers will be erected. However, the local government called for a "reserve land". The incident quickly spread through micro-blog. Many micro blog users discussed this matter, and forwarded this message. It leaded to the conflict between the villagers and the local government. In May 26, 2013, 13 villagers went to Beijing to complain, they went to the Ministry of land and resources [6].

We used PKUVIS that is visual analysis tool to analyze the event and get Figure 2. Figure 2 is a sail view. In Figure 2, the horizontal axis is time, vertical axis is forwarding relationship. We can see that the most of the forwarding was concentrated in front of that time, almost in the first time a large number of forwarding was issued. The number of forwarding was getting smaller and smaller over time. This result is consistent with the conclusions above. In the end people would be out of discussion and were not involved in the discussion any more. But the impact of this event was very large. This incident has damaged the credibility of the local government. The farmers had a heavy price to be paid.

\section{Suggestions}

All along, in China the control of network mainly manifests in the key words management, controls contact website and establish the related laws and regulations. Today, most countries are gradually opening up social networking sites such as Facebook, twitter, and so on. Can be seen, the gradual liberalization of the control of speech is the trend today. However, due to China's Internet popularity is higher, 600 million Internet users in China, more than 12 million mobile phone users, but the network participants is uneven, lack of restraint, It is obviously impractical to let go of the control of the network. On the one hand, we still need to strengthen the 


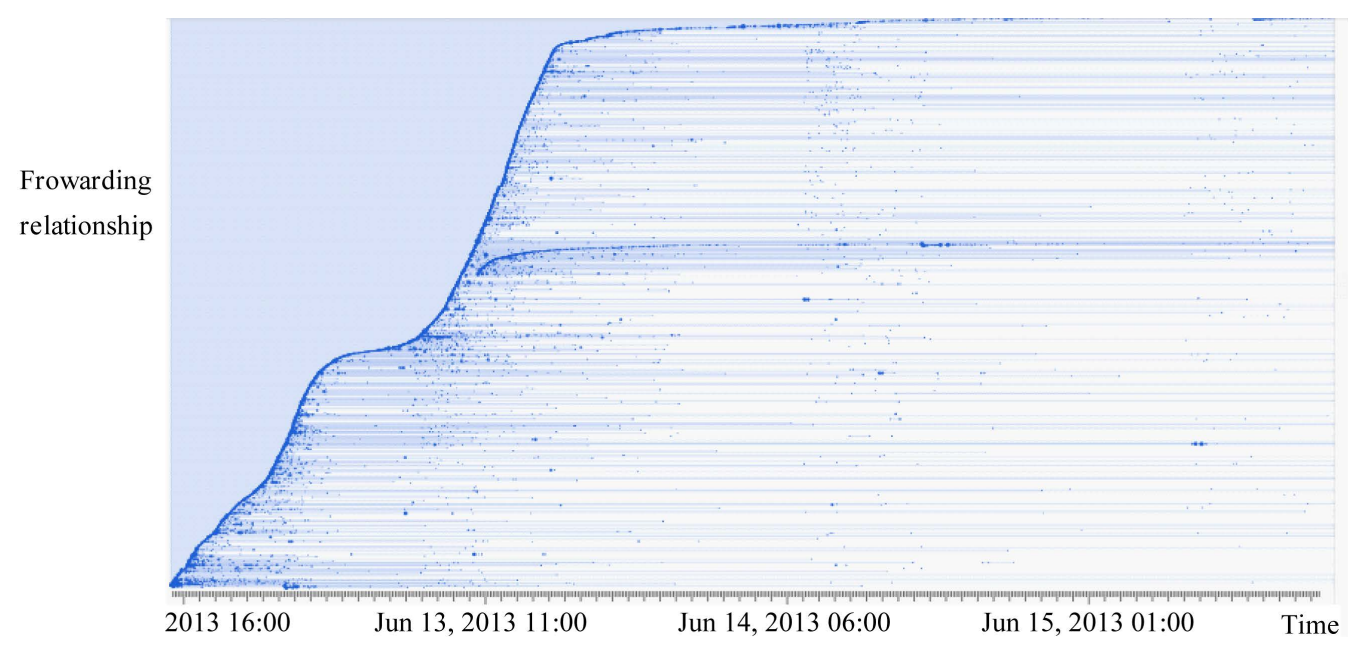

Figure 2. Sail view.

government's effective control over the network, on the other hand, we need to improve the overall quality of citizens. If citizens have the ability to judge right and wrong and does not have an ulterior by motive power control and utilization. Then the government proper guidance can ensure that public opinion does not affect the behavior of the government and social order, and guarantee the freedom of speech in a certain extent. So we can enhance the efficiency of the work of the government and prosperity of network culture.

According to the model, The first if we want to reduce influence events, we should reduced $S_{0}$, it is to improve $R_{0}$ (the immunity of the masses); the second way is to improve the threshold $1 / \sigma, \sigma$ is decreased, that is to reduce daily contact rate $k$, improved the cure rate of $h$. Then we discuss the ways to control group events of network.

\subsection{Increase the Moral Construction of the Masses}

According to the model, it can reduce the impact of the event by reducing the $S_{0}$, so that the event will not spread too quickly and widely. The government can better control public opinion. The government should strengthen management, so that people can immune change of the public opinion, and can improve the $R_{0}$. Influenced by public opinion and impacting on the public opinion depends largely on the degree of education, experience and occupation. In order to improve the degree of civic rationality, we should start from these aspects.

The government should intensify the ideological and political education and network self-discipline propaganda. The government should actively promote through reality, as well as various virtual web sites and establish a complete set of ethical standards. So citizens can discipline by themselves, can't believe the rumors, and actively prevent rumors. It is a positive role for the formation of a healthy network environment [7].

\subsection{Social Media Management}

\subsubsection{Perfect Internet Legislation}

Through the constraints of the law, it can help to ensure the rational behavior of the crowd, reduce the daily contact rate of $k$. Improve the Internet legislation, on the one hand we should ensure the norms of the content of the network, and on the one hand we should protect the legitimate rights and interests of Internet users. China launched the real name system in December 2011, if you have not the real name authentication, you will not be able to speak, forwarding, can only browse. Micro-blog real name system can help to track the source of speech, and help to clear Internet users' responsibilities and legal boundaries. But the control of speech and the "peopleoriented" concept of scientific development is contradiction. For example, the real name system may lead to loss personal information. The personal information was used by outlaws. Therefore, while we used the real name system, the micro-blog backstage should ensure the security of personal information of Internet users.

Since the Internet went into people's life, the relevant laws and regulations continue to produce. However, due to low cost of moral hazard on the network, any government can't invest a lot of manpower and resources to monitor every word, every picture. Therefore, the implementation of laws and regulations need to be streng- 
thened. Related departments and Internet service providers, such as micro-blog operators should cooperate to ensure the effective implementation of the laws and regulations of the Internet.

\subsubsection{Strengthen Information Disclosure System}

Strengthen information disclosure system make the masses quickly exit event, namely improving day cure rate $h$. One of the reasons of network group event is the information asymmetry between the people and the government. Such asymmetry can easily lead to distrust the government, and even attack the government. On the one hand, the government information to be sufficiently open and transparent, to strengthen interaction with Internet users. Today, every local government is established on the micro-blog official account. People more trust in the official message. Moreover, these official accounts to ensure that the views of the masses smoothly reach the government level. On the other hand, the government should clear channels of communication with the masses, to make the views of the masses smoothly reach the government. When the masses needs are not met, and threshold of gather comments on the network is very low, if the events happen, the cost of control is much higher than opening up channels of communication. At the beginning of the incident, the government should understand the problem, solve the problem. Government should take the initiative to provide information and communication channels to resolve conflicts caused by information asymmetry. It can resolve instability in society.

\subsubsection{Improve the Level and Method of Information Supervision}

Government should effectively guide and supervise speech, technology updates is essential. Now each platform mainly take keyword filtering way to prevent bad remarks published. It is worth noting that blindly remove the bad words is a form of passive avoidance, easily lead to mass distrust of the government. Government removes bad information at the same time, it is timely to guide the positive comments, the timely release of accurate information, in order to avoid excessive reaction from the crowd.

Secondly, the arrival of the "self-media" era, the network group events will only increase. The government should establish rational response mechanisms. The government should appoint professionals to take scientific statistical methods, to make scientific decisions. For sensitive and controversial topic, the government should quickly gather information, use the early warning systems and establish emergency response mechanism. It can help the government to reduce the probability of crisis caused by group events of network.

\section{Conclusion}

With the development of Internet, network group events happen more and more, and many hot topics evolve into group events of network. The government should pay particular attention to micro-blog. Micro-blog has become the most important platform of network group event. Although through modeling, we find that the group events of network always calm, but the scope of the event, time, capacity are still worth noting. Not just the government, any businesses, organizations are likely to be negatively affected from the network. Through scientific analysis of public opinion changes, timely prevention and effective control, regardless of the government or other organizations can better grasp of public opinion. In the end, public opinion can be correctly used by the government. Under premise of more rationality and freedom of speech, we can make social progress.

\section{Acknowledgements}

Research on the social science of the Ministry of Education, the research on the evolution mechanism of network group events and emergency strategy research under the micro blog platform, 13YJCZH124.

\section{References}

[1] Baidu Encyclopedia: Network Group Events. http://baike.baidu.com/view/2503424.htm?fr=aladdin

[2] Li, J.L. and Huang, Q. (2009) Challenge and Response: Government Information Management under the Network Group Events. Journal of Hunan University, 21, 34-39. (In Chinese)

[3] Data Source: Central Broadcasting Network. http://tech.cnr.cn/techgd/201403/t20140320_515115756.shtml

[4] Zhang, S.M. and Zhan, C.Y. (2011) The Impact of Network Public Opinion Dissemination on the Mass Emergency. Journal of Southwest University for Nationalities, 45, 65-70. (In Chinese)

[5] Cha, S.L. (2003) SIR Model of Infectious Diseases. Journal of Shanxi University of Traditional Chinese medicine, 25, 
13-18. (In Chinese)

[6] Chen, Y.H. (2010) Through “Handan Destroyed Wheat Event” to See the Spread of Micro-Blog. Media Observation, 8, 45-46.

[7] Qian, J.X. (2013) The Trigger Mechanism of Network Group Events and Government Response. Nanjing University, Nanjing. 